\title{
Peer Coordination and Communication Following Disaster Warnings: An Experimental Framework
}

\author{
Sera Linardi \\ Graduate School of Public and International Affairs \\ University of Pittsburgh \\ linardi@pitt.edu
}

\section{Acknowledgement}

This research is supported by National Science Foundation grant \#1331463: Hazards SEES Type 2: From Sensors to Tweeters: A Sustainable Sociotechnical Approach for Detecting, Mitigating, and Building Resilience to Hazards. 


\title{
Peer Coordination and Communication Following Disaster Warnings: An Experimental Framework
}

\begin{abstract}
The content of official disaster warnings is often lost to peer influence in emergency situations. This is also true in evacuation decisions, where people tend to leave when others leave, leading to miscoordination and congestion. The goal of this paper is to create an experimental framework to study how peer influence mediates the process through which human participants translate disaster warnings into evacuation decisions. The main design objectives are to 1) connect the field of disaster management to behavioral and experimental economics through social dilemmas, 2) establish a baseline treatment of no social interaction to first connect individual characteristics (namely risk preferences) to beliefs and actions, 3) measure the impact of enhancing peer to peer communication on collective evacuation patterns by systematically layering communication treatments upon the baseline treatment. An investigation of whether peer to peer communication can close the gap when official evacuation instructions fail to reach all residents is included as a sample application.
\end{abstract}

\section{Introduction}

It has been argued that dissemination of warning information from authorities to the public is not adequate to ensure a timely and orderly response. Those who receive official information do not always respond as expected. For example, the plans for Hurricane Rita called for sequenced evacuation that prioritized areas facing the most danger. However, many from communities under low risk evacuate anyway, creating a situation where "keep[ing] people off the road who don't need to be there" became a critical problem. ${ }^{1}$ As a result, some of those who are mandated to leave choose to stay rather than face what they expect to be a difficult and costly evacuation. Studies on evacuation decisions and dynamics reveal that the influence of authorities' instructions is indeed limited: official warnings only alert citizens to danger, but the informational content is often lost to peer influence (Eisenman et al., 2007; Burnside et al., 2007, Nilsson et al., 2009), Bode et al.,2012). Emergency management therefore needs to not only consider the role of vertical (top-down) communication, but also horizontal (peer-to-peer) communication (Comfort et al., 2004; Comfort, 2007).

Seen from the social science lens, the evacuation scenario resembles a social dilemma: acting in one's immediate self-interest is tempting, even though everyone benefits from acting in the long term collective interest. Specifically, it shares many characteristics with the tragedy of the commons, though there are enough important differences to warrant a separate investigation. ${ }^{2}$ Deutsch (1958) has found that a brief discussion prior to interaction increased subsequent cooperation in social dilemma; the importance of communication between participants in the dilemma has since then been confirmed in subsequent experimental studies. Baillet (2009) meta-analysis shows that communication affects understanding of the game, expectation of cooperation from others, group identity, and formation of norms. The idea that coordination can be greatly improved if warning systems are supported by self-emergent citizen communication networks (Umihara and Nishikitani, 2013) has produced an influential research agenda for emergency management. Special attention has been placed on

\footnotetext{
${ }^{1}$ See Evacuation Picked Apart In Houston, Rad Sallee, Houston Chronicle (www.chron.com), 27 Oct. 2005.

${ }^{2}$ Contrast an evacuation problem with overfishing, the classic commons example. The payoff for cooperating (refraining from overfishing) is increased fish stocks, which depends on the number of people who also refrain from doing so, while the payoff of overfishing can be considered independent from others' decision at least in the short term. On the other hand, the payoff from refraining from evacuating (facing the risk of catastrophic loss) can be considered independent from others' decision while the payoff for evacuating is decreasing in the number of people who evacuate.
} 
mobile technologies - "the next generation" in crisis response tools (Tepstra et al., 2012) - due to their potential for not only rapid one-on-one information transmission but also as a gateway to social media information broadcasts (e.g. Twitter).

However, the condition under which communication leads to positive self-organization in disaster evacuation is unclear. Existing empirical data on evacuation behavior from surveys, simulations, and agentbased models exist but they are not sufficiently fine-grained and are still "lacking systematic, individual-level experimental verification" (Moussaid et al., 2009, p.2755). ${ }^{3}$ Risk perception has been found to be the most important correlate of evacuation (Smalley, 2013; Burnside, 2006; Burnside et al., 2007; Bateman and Edwards, 2002); beyond that, people are much more likely to follow instructions, or conversely, disregard them, when others do so. Rapid communication capacity can therefore quickly render isolated instances of both compliance and noncompliance (e.g. evacuation of one extremely risk-averse person) into the prevailing norm. In addition, studies have shown that social media broadcast capacity can spread inaccurate information (Thomson et al., 2012) and be used to intentionally create harmful rumors (Castillo et al., 2011). In this situation, enhancing a community's ability to communicate internally may not improve welfare; in fact, peer-to-peer communication may even bring harm through confusion and misinformation. Whether the former or the latter best describes human actions in a disaster setting is a question that needs to be investigated systematically and empirically.

This paper intends to fill two gaps. First, it aims to provide a simple experimental framework to study how individuals translate official evacuation instructions into action when they are isolated from social influence. By including elicitation of individual characteristics (i.e risk preference) and beliefs about disaster probabilities and others' evacuations behavior, this framework can be used by researchers to trace the baseline process through which official instructions drive individual behavior. Second, it provides a way to systematically embed the individual in an increasingly complex social setting, revealing how local mechanisms shape collective patterns of behavior. In this experiment, each potential source of social influence (observation of nearby peers' behavior, 1 on 1 conversations, and broadcasted messages) is introduced as a separate experimental treatment that can be layered on top of each other. This allows researchers to isolate the impact of policy that utilizes social influence as a tool to improve evacuation outcomes, such as the enhancement of peer to peer communication capacity.

The approach in this paper links these questions to research in behavioral and experimental economics. Behavioral economics integrate psychological insights with a sharp focus on institution (as represented by information and incentives) in understanding human behavior. Experimental economics tests models of behavior by putting humans in strictly controlled experimental environments that replicate the basic information and incentives structure of the institution of interest. Due to its focus on replicability and micro-level causal mechanisms, this experimental approach may feel especially stark for researchers that are used to richer data from naturally occurring sources. However, its simplicity and self-contained nature allows subjects to participate in multiple rounds of the interaction of interest, generating data on the long run evolution of behavior. This is extremely valuable in studying behavior in response to disaster warning, where long run empirical data on the evolution of coordination and communication in a community under the threat of disaster may be very difficult and expensive to collect. ${ }^{4}$ Through a multi-round experiment we may find that a certain kind of communication technology (i.e broadcast) does not perform very well at first at improving evacuation responses, but then becomes very effective in the long run (i.e. as the pool of people who use broadcast technology shrinks and only the most effective leaders remains). ${ }^{5}$ Researchers can then investigate if these

\footnotetext{
${ }^{3}$ Findings from the standard commons problem, though useful, cannot be directly extrapolated to the evacuation setting due to important differences.

${ }^{4}$ Controlling for confounds such as changes in local government, evolution of communication technology, types of disaster, and the changing demographic of an area in this type of data is also challenging.

${ }^{5}$ For example, the ability to broadcast may get a community fully informed and energized to work together in overcoming the first threat of disaster, but may be used instead to protest and agitate as false alarms happen and past evacuation costs accumulate over
} 
experimental findings can be confirmed in more complex field experiments or site-specific studies before using it to inform policymaking.

In the next section (Section 2), I will provide a brief and necessarily incomplete review of the wide range of related literature. In Section 3, I will describe the information and incentives structure in the disaster scenario that motivates the experimental framework. I will also discuss the role of individual characteristics (i.e risk preferences) on the decisions to evacuate. Section 4.1 provides the basic experimental framework of evacuation decision without communication; sample computer screens are provided. Briefly, participants in the experiment are assigned to two districts that may be affected by an impending disaster. Evacuation costs increases in the number of evacuees, but is the only way to avoid suffering catastrophic losses in case of disaster. After observing private signals on disaster probabilities, an official aided by a computer system announces which of the districts has to evacuate. Participants then decide whether to evacuate. Section 4.2 discusses several extensions (Observation, Communication-1:1 and/or Broadcast, and Partial) that can be used to understand the conditions under which peer communication would improve evacuation coordination. Section 5 provides an example of how this framework can be used to investigate policy questions: whether peer to peer communication can close the gap when official evacuation instructions do not reach all residents.

\section{A Brief Overview of Literature and Methods}

Actual decision making in evacuations can be difficult to study since disasters happen rarely and real time data on interaction, communication, and movement is difficult to collect. Researchers have dealt with this challenge through two approaches: surveying individuals who lived in areas that were under evacuation orders due to an impending disaster, and studying actual evacuation decisions through scenarios simulated in real life or in computer games.

Surveys on evacuation are usually conducted with affected individuals during some period after the disaster by face-to-face interview or random direct dialing (RDD). The focus of these interviews includes: risk perception, information from media, local authority, and peers (Lindell, 2005); past evacuation decisions (“crying wolf"); evacuation obstacles such as transport (Eisenman et al., 2007); pets (Heath et al., 2001); and property, socioeconomic status, race and gender (Smalley, 2013; Burnside, 2006). Risk perception has been found to be the most important correlate of evacuation (Smalley, 2013; Burnside, 2006; Burnside et al., 2007; Bateman and Edwards, 2002) while the influences of other factors have so far been inconclusive. ${ }^{6}$ These studies have consistently found that social influence matters (Eisenman et al., 2007; Burnside et al., 2007). For example, Lindell (2005) finds that those affected by Hurricane Lili trusted information coming from peers most, followed by local authorities, and, finally, news reports.

Survey data, while allowing subjective questions to be asked about beliefs and expectations, is not as reliable on objective information as observational data. This may be due to recall bias (people remembering only certain aspects of their experience), subjective interpretation of interview questions, and social desirability bias (the desire to appear socially acceptable). ${ }^{7}$ Coupled with the lack of real (economic or other) incentives to tell the truth, social desirability bias makes it difficult to use surveys to uncover what individuals would actually do in a situation where normative judgments may be passed. For instance, one may say in a survey things like,

\footnotetext{
time. On the other hand, we might find that the ability to broadcast causes a great deal of confusion the first time it is introduced but becomes effective over time as trusted community leaders emerge.

${ }^{6}$ For example, Smalley (2013) found that African Americans are less likely to evacuate while Burnside (2006) did not find this to be the case. Similarly, while Benight (2004) and Burnside et al. $(2006,2007)$ found that having evacuated in the past when catastrophe did not happen (crying wolf) does not affect likelihood of evacuation in the future, Smalley (2013) finds that it does.

${ }^{7}$ See Holbrook and Krosnick (2010) on social desirability bias in voter turnout surveys; also see Holbrook et al. (2003).
} 
"I will risk my own well-being to assist my neighbors", "I understand that for the community to be safe, I must follow instructions", or "I am willing to stand up and do what is right, even when others do not", but he or she may not do so in an actual situation. ${ }^{8}$ When asked to make actual sacrifices for others, researchers have shown that when actions cannot be observed and judged, people take actions that are less dependent on the prevailing social norms (Jones and Linardi, 2014) and, sometimes, more selfish actions (Bohnet and Frey, 1999; Andreoni and Petrie, 2004; Bekkers and Wiepking, 2011). Conversely, public observation increases the sensitivity of prosocial behavior to herding (Linardi and McConnell, 2011).

Simulation offers a different source of information on human behavior (Schadschneider et al., 2009). Simulation studies are often focused on crowd dynamics and conducted by researchers in statistical mechanics, physics, computer science, and other fields. Some of them are extremely realistic, while others are less so. Nilsson et al. (2009) created a fake accident in a tunnel in order to test the role of wayfinding systems (lights and alarms). ${ }^{9}$ Fang et al. (2010), Was (2010), and Bode et al. (2014) ran experiments where students had to evacuate a lecture room. Was (2010) simulated a panicked state through competitive incentives for participants to evacuate first, while subjects in Bode et al. (2014) interacted through a computer game. ${ }^{10}$ Moussaid et al. (2009) conducted experiments with pedestrians performing simple avoidance tasks in order to determine the laws ruling their behavior during interactions. However, as stated in Moussaid et al., "... models of crowd dynamics are still lacking a systematic, individual-level experimental verification, and the local mechanisms underlying the formation of collective patterns are not yet known in detail.” (p.2755)

Human simulation connects agent-based models and surveys to actual human behavior. In most human simulations, humans are aware that they are not actually in an emergency situation and hence have a different incentive for their actions. A person who may behave recklessly in an actual emergency may be willing to follow instructions and patiently aid others in a simulated environment. This may be because concerns about being socially appropriate are strong enough to drive behavior when one's well-being is not actually at risk. This is not to say that simulations cannot replicate the incentives of an emergency situation. For example, the subjects in the hypothetical accident created by Nilsson et al. (2009) were unaware that it was not a real accident. However, an Institutional Review Board (IRB) is unlikely to grant permission for experiments in which human subjects are led to believe that they are in danger. Another option is running simulations that are realistic enough to make the participants feel like they are in the real situation. These realistic simulations are, however, quite costly and complex to put together.

The controlled lab experimentation method common in behavioral and experimental economics is very close in spirit to this simulated environment. The challenge for researchers in both fields is to preserve the incentive and informational structure of the environment that is being studied, while abiding by ethical, cost, and resource constraints. Experimental economists are additionally concerned with replicability and ability to isolate micro-level causal mechanisms. The tradeoff between the realism and abstraction inherent in this approach may feel especially stark for researchers from other fields. One must remember, however, that lab experiments are not intended to be the end of the investigation but only to provide a basic framework upon which richness and complexity can be layered.

\footnotetext{
${ }^{8}$ Glaeser et al. (2000) showed that attitudinal trust questions do not predict real trusting behavior in controlled experiments where people have to trust others to return their investment.

${ }^{9}$ Nilsson et al. (2009) found that public information (prerecorded alarm with instructions) alerted motorists to the danger, but much of the informational content was lost. Social influence was essential in both the decision to leave the vehicle and the choice of exit. Stress/arousal level influences the amount of information noticed by motorists.

${ }^{10}$ In the Bode et al. (2012) game, participants had to choose between different exit routes under the (separate and combined) influence of three different types of directional information: static information (signs), dynamic information (movement of simulated crowds) and memorized information. The results suggest that social information that confirms beliefs can negate official information.
} 
Connecting the evacuation problem to the behavioral and experimental economics literature presents an interesting challenge in that it shares a number of features with many well-studied problems but combines them in a way that is rarely studied. For example, as the Hurricane Rita situation illustrates, an evacuation situation is not just a social dilemma but also a multiple-group nested dilemma (Wit and Kerr, 2002), wherein individuals are member of subgroups (districts) which in turn are part of a superordinate group (the larger community under risk). Payoffs are more interdependent for those who consume the shared resource (evacuation) than those who refrain from doing so (staying). Though authorities are privy to some private signals before disaster occurs, the uncertainty environment is essentially unknowable (Chow and Sarin, 2001), and the public learns little beyond whether or not the disaster occurred. A comprehensive survey of the large range of social science research that the evacuation environment touches upon would be beyond the scope of this literature review. This brief summary will therefore focus only on the three most relevant areas: social dilemmas, social information, and information transmission.

There are various conceptualizations of the role of risk in social dilemmas (Au et al., 2012); perhaps the most relevant to our setting is Van Assen and Snijders (2004), where risk is defined as a person's preference between a sure thing and a gamble with the same expected value. Combining prospect theory and game theory, the authors formally showed that when cooperation is in the loss domain (as in settings where one is asked not to evacuate) the likelihood of cooperation decreases with risk aversion.

Baillet's (2009) meta-analysis suggests that communication may be one of the most promising engines of cooperation in social dilemmas. A large positive effect size is found whether communication occurred faceto-face or in written form, and before or during iterated dilemmas. Even more promising, the communicationcooperation relationship is stronger in larger group social dilemmas, where cooperation is traditionally harder to achieve. Though the content of the communication is not analyzed in Balliet (2009), studies of iterated social dilemmas suggest that it may have been used to establish norms. These iterated games point to the importance of rewards and punishment in cooperation, especially when administered by fellow participants rather than authorities (Van Lange et al., 2013). Ostrom (1990), for example, focuses on the importance of local monitoring, sanctioning, and reward, with reciprocal strategies developing over the long run.

While a lot of laboratory experiments study the behavior of individuals who make decisions in isolation, real-life decisions are made under peer influence. Previous literature on the impact of peer effects on financial decision making has identified two types of information relevant for risky decisions (Duflo and Saez, 2002; Duflo and Saez, 2003; Mobius et al, 2005): decision information (observation on what peers are doing) and advice (reasoning). They find that while the former are likely to cause herding, ${ }^{11}$ the latter allows people to make better, more accurate decisions. The experimental framework in the next section will first extend the individual decision-making context to one in which subjects can see what their neighbors have chosen. Since this is decision information, the literature above warns of the possibility of herding. In their review of human motivation and social cooperation, Fehr and Gintis (2007) show that self-regarding and norm-regarding actors coexist. While the self-regarding individual will only use peer action for instrumental effect (e.g. to better estimate the number of people evacuating), norm-regarding people are additionally concerned with following the actions of their peers (e.g. inferring that since everyone is staying, it is what one is expected to do). ${ }^{12}$ This norm-abiding effect is strengthened when one takes into account the fact that others are observing their behavior (Jones and Linardi, 2014), leading to cascades of behavior (Linardi and McConnell, 2011).

What is the effect of non-decision information? Chaudhuri et al. (2006) study the contribution to the public goods game given intergenerational advice and found that common advice (advice that is read out loud by the experimenter) is more effective at decreasing free-riding than private (from one player to another) or

\footnotetext{
${ }^{11}$ This is also referred to as weak social learning (Mobius et al., 2005).

${ }^{12}$ The degree to which observation will cause herding therefore depends on the distribution of these two types in the population.
} 
public (from one player to all) advice. Though this setting has many similarities to our investigation of different types of communication - namely the use of official evacuation instructions, 1-on-1 messaging, and broadcasts - our research question takes the presence of common advice as given and investigates the marginal benefit of combining it with private or public advice. Studies like Ostrom (1990) suggest that the capacity to give private and public messages to peers in this setting would not be redundant and will likely be used for local monitoring, sanctioning, and reward.

Now who would transmit information to whom? Candelo et al. (2013) find that information about others' actions has the greatest impact when its source is a distant social contact but advice is most often provided and accepted from close sources. Gino et al. (2009) also find that similarity between the source of advice and the person receiving the advice matters when it regards one's own action. This implies that one will transmit and listen to advice from people in a situation most similar to her own, but will transmit and pass on decision information about others to people distant from herself. Related to this, Leider et al. (2009) find that directed altruism (to friends and family) is far larger than baseline altruism (to strangers), so if information transmission is costly (in terms of money, time, or effort), people will send information only to help those they know and like. Indeed Berger et al. (2015) find that as a potentially stressful event approach mobile phone activity shifted towards phones that share the same providers and are geographically closer. As a result, making communication more accessible may actually tighten group ties and increase intra-group distances (Rosenblat and Mobius, 2004).

The next section describes an evacuation scenario that motivates the experimental design in Section 4. Note that this extremely simplified environment is only intended to capture the crucial element of uncertainty and coordination in evacuation, and does not actually depict a real disaster.

\section{Disaster Environment}

Sensors have detected that a disaster (e.g. hurricane, tsunami) may be coming and may either hit one of two neighboring districts, $\mathrm{X}$ and $\mathrm{Y}$, or miss both completely. ${ }^{13}$ The two districts share the same infrastructure for evacuation (i.e. highways and public transit out of the area). Due to congestion, the cost of evacuation is an increasing function of the total number of residents evacuating from both districts. All available information on the potential disaster enters a computer system that issues one of four evacuation instruction: (E(vacuate), E), (S(tay), E), (E,S), or (S,S), where (E,S) means that district X should evacuate while district Y should shelter in place. The computer arrives at the instructions by computing the probability of disaster for each district and comparing expected disaster losses against expected evacuation cost.

The size of the population of district $\mathrm{X}$ is denoted as $\mathrm{nx}$, with ex representing the number of evacuees from that district and $q_{x}$ representing the computer's estimate for the probability that disaster will befall district $\mathrm{X}$. Let $\mathrm{n}_{\mathrm{Y}}$, ey, and $\mathrm{q}_{\mathrm{y}}$ represent the corresponding quantities for district Y. For simplicity, assume that all individuals in both district have a wealth of $\mathrm{w}$ and face either the catastrophic losses due to the disaster of $\mathrm{C}$ or the potential cost of evacuation of $c\left(e_{x}+e_{y}\right)$ where $c>0$ is a constant. ${ }^{14}$

In determining the optimal evacuation warning, the computer system needs to make several assumptions about human behavior. First, the system must choose some numerical representation of how people evaluate outcomes under risk. The choice of the utility function does not change the discussion that follows, but for concreteness, I assume the Constant Relative Risk Aversion (CRRA) utility function that is commonly used in economics, where the utility of the payoff of $x$ for a person of risk parameter $r$ is $\mathrm{u}^{\mathrm{r}}(\mathrm{x})=\mathrm{x}^{(1-\mathrm{r})} /(1-\mathrm{r})$. Risk

\footnotetext{
${ }^{13}$ Assume that the disaster cannot hit both districts.

${ }^{14}$ In reality, congestion cost is probably exponentially increasing in evacuees, since overwhelmed infrastructures result in additional failure that compounds the problem (e.g. cars overheating from sitting in traffic). See Litman (2007)
} 
aversion is indicated with $r>0$ while risk- seeking behavior is indicated with $r<0$. Second, the computer system needs to make assumptions about how citizens respond to the messages. For simplicity in the present case, the system assumes compliance to instructions: that is, when message (E,S) is issued, everyone from $\mathrm{X}$ will evacuate while no one from Y will. ${ }^{15}$

Letting $\mathrm{r}^{*}$ be the risk tolerance assumed by the computer system, the expected total welfare from announcing the four possible messages are:

$$
\begin{aligned}
& \left.\mathrm{EU}(\mathrm{E}, \mathrm{E})=\left(\mathrm{nX}_{\mathrm{X}}+\mathrm{n}_{\mathrm{Y}}\right) \mathrm{u}^{\mathrm{r} *}\left(\mathrm{w}-\mathrm{c}\left(\mathrm{n}_{\mathrm{X}}+\mathrm{n}_{\mathrm{y}}\right)\right)\right) \\
& \mathrm{EU}(\mathrm{E}, \mathrm{S})=\mathrm{n}_{\mathrm{X}} \mathrm{u}^{\mathrm{r}^{*}}\left(\mathrm{w}-\mathrm{cn}_{\mathrm{X}}\right)+\mathrm{n}_{\mathrm{Y}}\left(\mathrm{qY}_{\mathrm{Y}} \mathrm{u}^{\mathrm{r}^{*}}(\mathrm{w}-\mathrm{C})+(1-\mathrm{qY}) \mathrm{u}^{\mathrm{r}^{*}}(\mathrm{w})\right) \\
& \mathrm{EU}(\mathrm{S}, \mathrm{E})=\mathrm{n}_{\mathrm{X}}\left(\mathrm{qX}_{\mathrm{X}} \mathrm{u}^{\mathrm{r}^{*}}(\mathrm{w}-\mathrm{C})+\left(1-\mathrm{qX}_{\mathrm{X}}\right) \mathrm{u}^{\mathrm{r}^{*}}(\mathrm{w})\right)+\mathrm{n}_{\mathrm{Y}} \mathrm{u}^{\mathrm{r}^{*}}(\mathrm{w}-\mathrm{cn} \mathrm{c}) \\
& \left.E U(S, S)=\left(n_{X} q_{X}+n_{Y} q_{Y}\right) u^{r^{*}}(w-C)+\left(n_{X}\left(1-q_{X}\right)+n_{Y}\left(1-q_{Y}\right)\right) u^{r^{*}}(w)\right)
\end{aligned}
$$

Let $\mu$ be the message that produces the highest expected utility among the four in the comparisons above. This is the official evacuation instruction sent to everyone. Assume the message reaches each individual in its entirety regardless of the district in which they reside; for example, a person in District $\mathrm{X}$ knows what $\mathrm{Y}$ is asked to do. ${ }^{16}$

Left on their own, residents have little objective information about the disaster; it is known that the government is privy to much better information through research and monitoring. However, because not everything related to the disaster can be detected, these estimates are not always correct. It is also known that the government does not punish those who disobey evacuation instructions (such as those who stay when asked to leave or leave when asked to stay). Also assume that the authorities have set $r^{*}$ to be the risk preference of the average person in the population. ${ }^{17}$

Suppose the process through which the instruction is arrived at (Eq. (1)) and all inputs into the decision problem $\left(\mathrm{c}, \mathrm{C}, \mathrm{nx}, \mathrm{ny}, \mathrm{r}^{*}\right)$ are common knowledge except for disaster probabilities qx and qy. ${ }^{18}$ A person may not comply with evacuation instructions for the following reasons: 1) she is not concerned with maximizing total welfare; 2) her risk preference is different from the average person in the population $\left(\mathrm{r}^{*}\right)$; 3 ) her estimates of the disaster probabilities given the instructions are erroneous; and 4) she expects others not to comply with the message $\mu$, thereby changing the number of evacuees and, correspondingly, the cost of evacuation. For example, upon receiving $(\mathrm{E}, \mathrm{S})$ district $\mathrm{X}$ residents may not evacuate because they anticipate district $\mathrm{Y}$ will ignore instructions and attempt to evacuate anyway, thus making the roads impassable for X.

Equation 2 below formalizes the cost-benefit calculation of a person in District $\mathrm{X}$ who has received instruction $\mu$ calculated under risk parameter $r^{*}$. Letting $\operatorname{Pr}\left(\mathrm{X} \mid \mu, \mathrm{r}^{*}\right)$ be her estimated probability that the disaster hits District $\mathrm{X},{ }^{19} \mathrm{E}\left[\mathrm{ex}+\mathrm{ey} \mid \mu, \mathrm{r}^{*}\right]$ be her expectation of the total number of evacuees, and $\mathrm{r}_{\mathrm{i}}$ be her own risk preference, her expected utility of evacuation and staying are, respectively:

$$
\left.\mathrm{EU}^{\mathrm{i}}\left(\text { Evacuate } \mid \mu, \mathrm{r}^{*}\right)\right)=\mathrm{u}^{\mathrm{ri}}\left(\mathrm{w}-\mathrm{cE}\left[\mathrm{ex}+\mathrm{ey} \mid \mu, \mathrm{r}^{*}\right]\right)
$$

\footnotetext{
${ }^{15}$ Hence when message $(E, S)$ is issued, $e_{x}=n_{x}$ and $e_{y}=0$. This is not an equilibrium, but it is quite likely that the system does not incorporate game theoretic considerations in issuing messages.

${ }^{16}$ This is a reasonable assumption because official disaster warnings often arrive through mass media such as TV or radio, such that those who receive the information are aware of instructions for other districts.

${ }^{17}$ Holt and Laury (2002) and Eckel and Grossman (2002) find that majority of people are risk averse, with the average $r$ around 0.70 for the CRRA utility function.

${ }^{18}$ In real life, people may not know exactly what these numbers are but would have an estimate.

${ }^{19}$ Note that the estimate depends on the risk tolerance adopted by the government. For example, $\operatorname{Pr}\left(X \mid(S, E), r^{*}\right) \operatorname{must}$ be extremely low if District $X$ is asked to stay by an extremely risk-averse government. Estimates on the number of total evacuees also depends on beliefs about others' risk preferences, in particular, the distribution of risk preferences in Districts $\mathrm{X}$ and $\mathrm{Y}$.
} 


$$
\mathrm{EU}^{\mathrm{i}}\left(\operatorname{Stay} \mid \mu, \mathrm{r}^{*}\right)=\operatorname{Pr}\left(\mathrm{X} \mid \mu, \mathrm{r}^{*}\right) \mathrm{u}^{\mathrm{ri}}(\mathrm{w}-\mathrm{C})+\left(1-\operatorname{Pr}\left(\mathrm{X} \mid \mu, \mathrm{r}^{*}\right)\right) \mathrm{u}^{\mathrm{ri}}(\mathrm{w})
$$

From the above, it is clear that an individual's compliance to evacuation instructions depends on how her risk preferences $\left(\mathrm{r}_{\mathrm{i}}\right)$ compare to that of the average person $\left(\mathrm{r}^{*}\right)$ and her estimate of the number of people evacuating. Table 1 summarizes the behavioral prediction. ${ }^{20}$ Those who are risk seeking are predisposed towards riding out the disaster (Row 1): they are the ones who are most likely to comply when asked to stay, and the least likely to comply when asked to evacuate. On the other hand, those who are risk averse are predisposed towards evacuating (Row 3 ) and hence are most likely to contribute to over-evacuation.

Table 1. Behavior given evacuation instruction as a function of risk preference

\begin{tabular}{|l|l|l|l|l|}
\hline & \multicolumn{3}{|l|}{ District X asked to evacuate } & \multicolumn{2}{l|}{ District X asked to stay } \\
\hline $\begin{array}{l}\text { Resident of X } \\
\text { who is }\end{array}$ & (E,E) & (E,S) & (S,S) \\
\hline $\begin{array}{l}\text {...more risk } \\
\text { seeking than } \\
\text { average (ri<r*) }\end{array}$ & $\begin{array}{l}\text { May not } \\
\text { comply if } \\
\text { expects all to } \\
\text { complies. }\end{array}$ & $\begin{array}{l}\text { May not } \\
\text { comply if } \\
\text { expects some in } \\
\text { Y not to comply }\end{array}$ & $\begin{array}{l}\text { Likely to } \\
\text { comply }\end{array}$ & Will comply \\
\hline $\begin{array}{l}\text {... average in } \\
\text { risk tolerance } \\
\text { (ri=r*) }\end{array}$ & Will comply & $\begin{array}{l}\text { Likely to } \\
\text { comply unless } \\
\text { expects many in } \\
\text { Y not to comply }\end{array}$ & $\begin{array}{l}\text { Likely to } \\
\text { comply unless } \\
\text { expects many in } \\
\text { Y not to comply }\end{array}$ & $\begin{array}{l}\text { May not } \\
\text { comply if } \\
\text { expects all to } \\
\text { comply }\end{array}$ \\
\hline $\begin{array}{l}\ldots . \text { more risk } \\
\text { averse than } \\
\text { average } \\
\text { (ri>r*) }\end{array}$ & Will comply & Will comply & $\begin{array}{l}\text { May not } \\
\text { comply if } \\
\text { expects some in } \\
\text { Y not to comply }\end{array}$ & $\begin{array}{l}\text { Will not } \\
\text { comply }\end{array}$ \\
\hline
\end{tabular}

Once the evacuation instruction is issued, people have a limited amount of time to make up their minds to evacuate. Not doing so in time is equivalent to staying. Once the time has elapsed, residents learn a limited amount of information. They learn whether the disaster happens to one of the districts, or if threat passes without incident. Those who evacuated also learn about the number of people who evacuated and pay the cost of evacuation. Those who experienced the disaster suffer the catastrophic cost. This may change the way they respond to future evacuation warnings.

The description above illustrates the basic disaster environment wherein every individual receives official evacuation instructions and responds to it without peer influence. The baseline design (Section 4.1) will model this situation as the Fully Informed Treatment (Full). The experiment will not only observe individual evacuation decisions given disaster warnings, but also elicit each individual's risk preference $r_{i}$ as well as her estimates of disaster probabilities and estimated number of evacuees. In this way we can link risk preferences, beliefs, and action in a basic evacuation framework before systematically layering various forms of peer influence.

In a reality evacuation decisions are very much influenced by observation of nearby peers, which may be in accordance with, or in direct opposition to, instructions. In the recent years the widespread adoption of mobile devices guarantees that cell phones will be ringing and SMSs will be sent. The recent influence of social media such as Twitter and Facebook adds an extra layer of communication, with all messages being broadcasted to everyone. ${ }^{21}$ These last two forms of communication are free-form, potentially containing real

\footnotetext{
${ }^{20}$ Numerical simulation of Table 1 is available upon request.

${ }^{21}$ Generally, when communication is initiated by one side, the other side will receive it: most text messages are received by their intended recipient and messages posted on social media are usually widely read by the audience for whom it is intended.
} 
information, cheap talk, speculation, or social interaction unrelated to evacuation. Following the insight from Ostrom, (1990) and Van Lange et al. (2013), the combination of communication capacity and the ability to observe and be observed by peers may give rise to local monitoring, punishments, and rewards, which may sustain cooperation over the long run.

\section{Experimental Design}

\subsection{Baseline Treatment}

The design of this framework is guided by several factors. First, it needs to be adaptable to different disasters and environments while capturing the core decision problem in an evacuation setting. Second, the implementation must not require high technological or organizational capacity. Third, the experiment must be simple enough such that participants with low levels of education and technological sophistication are able to participate. This ensures that the data can be regenerated and expanded by any interested institution to study any population. Therefore, even though the experiment that will be described below utilizes networked computers, this design is such that the experiment can be easily performed on pen and paper. ${ }^{22}$

The following will describe the general experimental setup. The researcher can determine the total number of rounds played; a 6 round game would take approximately one hour with every round taking about 510 minutes. This experiment implements gains and losses as points which can then be translated to real incentives such as physical discomfort, monetary losses, or loss of time after the final round. ${ }^{23}$ Sample computer displays are given in Figure 1,2 and 3. Participants are recruited in advance in order to represent a random sample of the communities of interest. A person in a position of authority (such as a government official) is also recruited. All participants are seated in front of networked computers. Their risk preferences first are elicited at the start of the session through one of the standard experimental procedures in Charness, Gneezy and Imas (2013). The modal risk preference is computed and then announced to all and entered into the authority figure's computer system. Subjects are then randomly assigned to one of two districts, X and Y. This assignment can be random, or, not, for example, if subjects are purposefully recruited from two communities whose interaction is the subject of interest. Subjects' computer screen is displayed in the left panel of Figure 1. Subjects know who they are by the circle on the district map. For example, the picture in Fig 1 is the computer display for subject number 5. It shows that she is in District $X$ and her neighbors are subjects 3,4, and 6. All subjects retain the same role for all rounds.

\footnotetext{
22 The experiment described below utilizes networked computers, however, it can also be conducted on pen and paper. Additional research assistants will be needed to pass decision, information, and messages by hand.

${ }^{23}$ This experiment implements gains and losses as points which can then be translated to real incentives such as physical suffering, monetary losses, or loss of time. Physical suffering in experiments has been implemented as electric shocks or putting one's hand in an ice bucket. Monetary losses can be implemented by allowing participants to earn money through a task, and then taking away a small part of this earning as the cost of evacuation or all of it in the case of disaster. Loss of time can be simulated by requiring participants to perform a boring task for some time. A large literature exists on how monetary gains and losses motivate behavior. Less is known about the other two, though research finds that people are more risk averse with physical pain than with monetary losses (Rottenstreich and Hsee, 2001) and with money than with time (Abdellaoui and Kemel (2013)).
} 


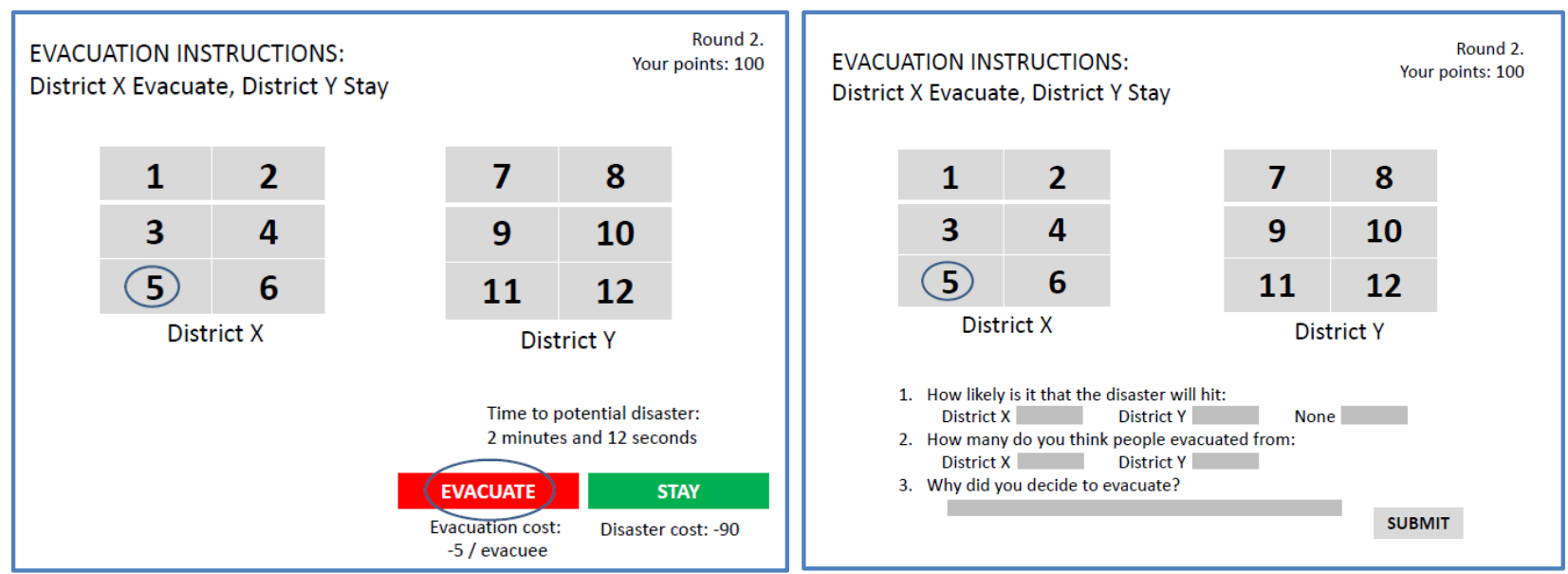

Figure 1: Baseline computer screen. Left panel illustrates Subject 5's decision making screen. Right panel illustrates her belief elicitation screen.

Participants are then introduced to the uncertainty setting. This is designed to represent unknowable probabilities (Chow and Sarin, 2002) where no one, including the experimenter, knows the probability distribution from which the disaster will happen. ${ }^{24}$ This is implemented as follows: there are 3 urns with different numbers of marked chips, visible to everyone. Just for illustration purposes, suppose one urn has $3 \mathrm{X}$ chips, 6 Y chips, and 3 unmarked chips. This represents that probability distribution of the disaster afflicting district $X, Y$, and neither is $(1 / 4,1 / 2,1 / 4)$. The second urn has $3 X$ chips, 3 Y chips, and 6 unmarked chips. The third has $6 \mathrm{X}$ chips, $3 \mathrm{Y}$ chips, and 3 unmarked chips. After subjects get a chance to inspect all urns, the content of each urn is transferred into unmarked, identical bags. All 3 bags are placed in a larger bag.

A round starts with a randomly selected subject drawing a bag from the larger bag and placing it behind a screen. This is bag from which the realization of the disaster will be drawn from (Bag T). The authority figure draws a pre-specified number of chips from the bag behind the privacy of the screen and enters his observation into the computer. The computer conducts the computation of qx and qy given the authority's private signals and outputs the optimal message to all the computers in the room given the calculations in Eq (1). A sample message would be "District X Evacuate, District Y Stay" - as discussed in Section 3.1 there are four possible messages.

As illustrated in the left panel of Figure 1, the evacuation instruction is shown on top of all subjects' computer screen. Subjects then have a limited amount of time (i.e, 3 minutes) to make a decision on whether to evacuate or to stay. The buttons to evacuate is underneath the countdown clock on the right bottom corner. The cost of evacuation as a function of congestion as well as the cost of experiencing the disaster if one does not evacuate is displayed on the screen so that subjects can easily refer to them. Once a subject has made his choice, subjects' belief regarding the likelihood of disasters and compliance of both districts are elicited (Figure 1 Right panel). ${ }^{25}$

After the countdown clock indicates the end of the decision making period, one chip is randomly drawn from Bag T and shown to all subjects. If the chip is marked with an X, the disaster has hit District X. Similarly, if the chip is marked with a Y, the disaster has hit District Y. If chip is blank, the threat of disaster has passed without incident. Suppose the drawn chip is marked with an $\mathrm{X} .{ }^{26}$ The left panel of Figure 2 shows the screen of

\footnotetext{
${ }^{24}$ Chow and Sarin (2001) show that asymmetric information between anyone and the participants generate decisions that look like ambiguity aversion but they are the result of aversion to asymmetric information.

${ }^{25}$ For a review of belief elicitation methods in experimental economics, see Schotter and Trevino (2014).

${ }^{26}$ The authority figure would manually enter information on the drawn chip into the computer.
} 
subject 5 if she had clicked on Evacuate before the time is up. The screen shows the total number of evacuees and her corresponding evacuation cost. The right panel of Figure 2 shows her display if she had not clicked on Evacuate before time is up. Since she did not leave, she does not know the number of people who evacuated. Her total points (in the right upper corner) decrease according to her action and the realization of the disaster. This information concludes the period. The chip is returned to the bag, the bag is returned to the larger bag, and a new bag is drawn for Round 2 .
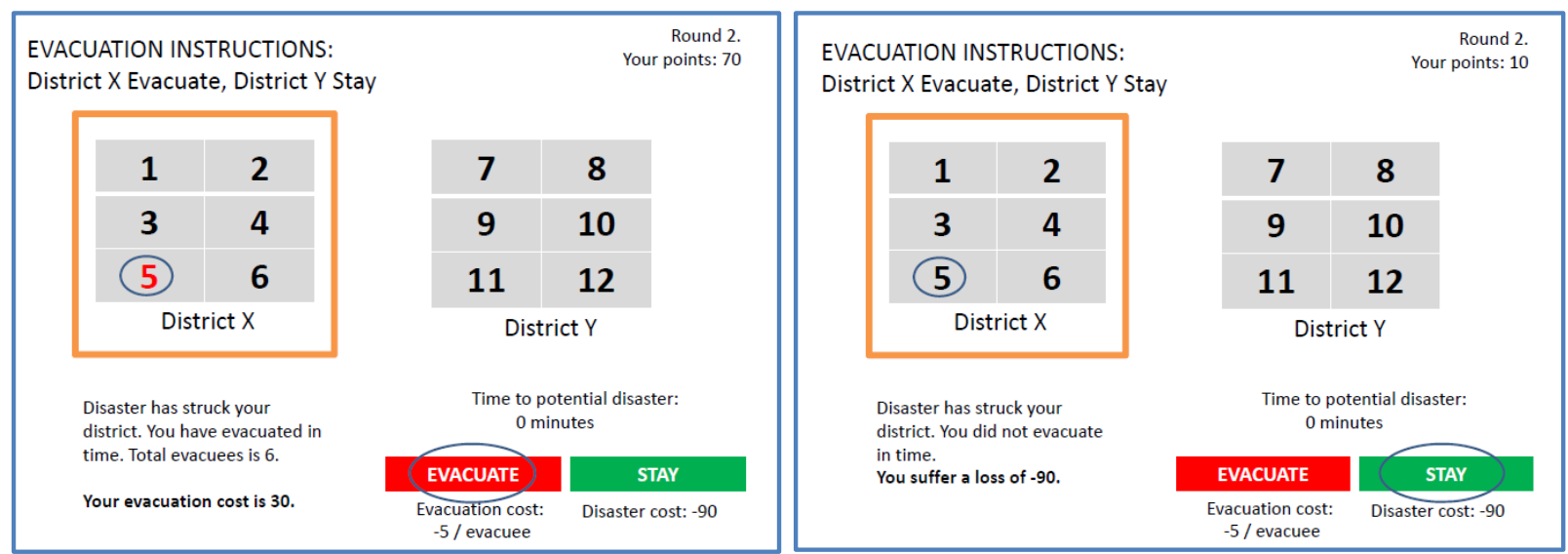

Figure 2: Baseline computer screen. The screen of Subject 5 in the event that chip $X$ is drawn is illustrated in the Left panel (if she evacuated) and the Right panel (if she did not).

\subsection{Extensions of the Baseline Treatment}

Section 4.1 illustrates the basic disaster environment where every individual receive official evacuation instructions and respond to it without peer influence. This baseline design allow us to rigorously build upon survey findings on the importance of risk perception on evacuation, by allowing us to experimentally observe how risk preferences influence the way evacuation warnings get translated into beliefs about the disaster and others' behavior, and ultimately, evacuation decision. Establishing this understanding provides a baseline on which we can study the impact of social observation and communication. Below I will discuss several extensions to the baseline model: Observation, Communication (1:1 or Broadcast), and Partial.

In the Observation treatment, the color for a participant's immediate neighbors is either red or green, indicating whether or not they have evacuated. One cannot, however, visually observe the decision of the neighbor of a neighbor (non-immediate neighbors). The color for a participant's non-immediate neighbors is therefore gray, indicating lack of information. ${ }^{27}$ To represent the geographical limitation of visual observation, one cannot observe the behavior of people from a different district. Figure 3 illustrates the computer screen for Subject 5 in the Observation treatment. The grid informs him that Subject 3 and 6 has evacuated, while Subject 4 has not.

\footnotetext{
27 To operationalize participant i's direct observation of his neighborhood at time t without computers, the researcher can control spacing between desks and the placement of partitions. Participants must stay in their seats but can look around them to see the color of the cards on their neighbors' tables before deciding what to do.
} 


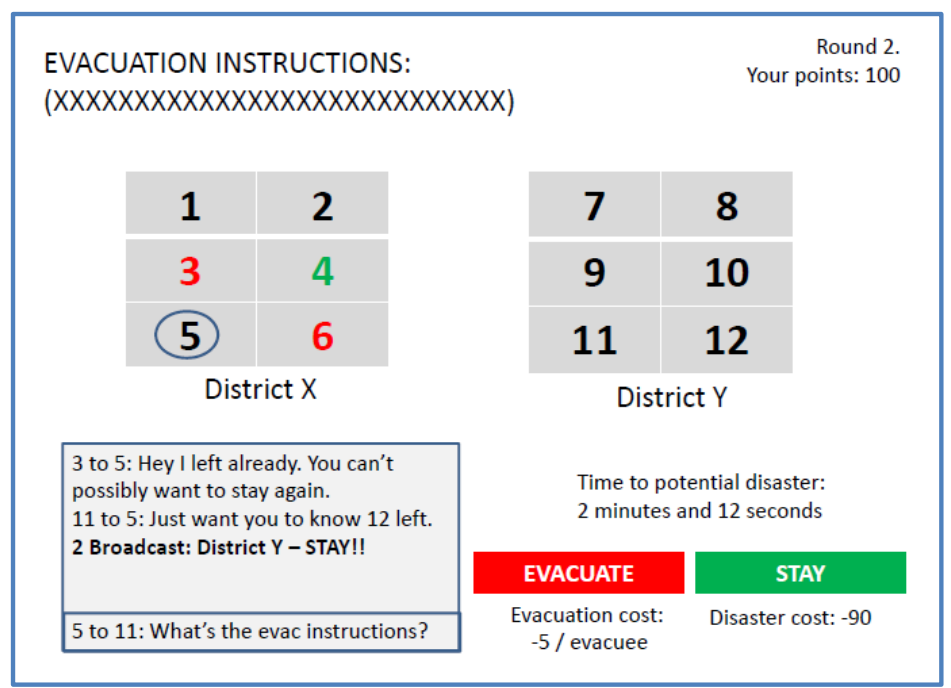

Figure 3: Computer screen in Partial with Observation, 1-1, and Broadcast.

In the Communication treatment, participants can communicate through a chat box on the bottom left of the screen. The chat capability is present for the entire decision making period. Depending on the setting that the researcher is interested in, a cost of sending messages could be implemented. In 1:1 communication, participants can send messages to only one person at a time. To represent how mobile phone allows communication across geographical distance, 1:1 communication can be sent to anyone regardless of their district of residence. They do so by clicking on the cell on the map that indicates their intended recipient. The chat box in Figure 3 shows Subject 5's screen after she clicks on Subject 11's cell and typed the message "What's the evac. instructions?". In Broadcast, any messages sent by the participant will appear on all participants' chat box in bold text. Figure 3 illustrates how the screen will appear if Subject 2 sent a broadcast saying "District T - STAY!!". The content of these free-form messages are recorded as part of subjects' behavior that would be analyzed after the experiment. ${ }^{28}$

The last extension discussed here is the Partial treatment. In this treatment, only $0<\alpha<1$ of the participants observe the evacuation instructions from the authority. Figure 3 illustrates Subject 5's screen if she was among the 1- $\alpha$ (who did not receive the message.) Instead of text, her evacuation instructions will only show a row of XXXX. This represents the limitation of official information; not everyone can be reached through the official channels of communication. The comparison between Partial and Full, under various communication treatments can reveal the extent to which peer to peer communication can make up the gaps from official communication.

There are several ways to compare outcomes across treatments. The first obvious measure is to compute compliance for a given warning and compare this across treatments. For example, full compliance to the message $(\mathrm{E}, \mathrm{S})$ would be $\mathrm{eX}=\mathrm{nX}$ and $\mathrm{eY}=0$. Suppose we observe that in Full that $70 \%$ of District $\mathrm{X}$ and $35 \%$ of district $\mathrm{Y}$ evacuated, while in Full with Broadcast $100 \%$ of X and $70 \%$ of Y evacuated. This indicates that compliance in Full is $(70 \%, 65 \%)$ for District $\mathrm{X}$ and Y respectively and compliance in Full with Broadcast is $(100 \%, 30 \%)$. Being able to communicate through broadcast has then increased compliance in the district that is supposed to evacuate and decreased it in the district that is supposed to shelter in place. A second way is to compare payoffs, such as average payoff of residents from both districts, the difference in average payoffs across both districts, or other statistics. A third way is to compare the accuracy of elicited beliefs about disaster probabilities and number of evacuees. The impact of adding a communication capacity to a specific environment can then be comprehensively measured by comparing the three outcome measures in the treatment with and without the communication.

\footnotetext{
${ }^{28}$ For an example of chat text analysis in experimental economics, see Brandts and Cooper (2007).
} 


\section{Discussion}

Studies have shown that in a disaster environment, official information on what to do is often lost and people react to the potential danger by following their peers. There is therefore a need to systematically study the interaction of official (vertical) communication with peer to peer (horizontal) communication. This paper pursues two contributions. First, it provides an experimental framework to investigate how individuals translate evacuation warnings into action independent of peer effect. Second, it provide extension to the basic framework to layer various sources of social influence (such as one on one communication, broadcasted messages, or visual observation of nearby peers), systematically embedding the individual within an increasingly complex social environment. This allows us to understand the marginal impact of policy intervention that changes the ability of peers to interact, such as communication technology.

There are many ways to use this experimental framework. One application might be to investigate whether peer-to-peer information can close the gap when not everyone can be reached through the official disaster warnings. Official information may not reach all residents for several reasons. First, not everyone owns a receiver for the medium through which the warning is transmitted (e.g. a TV or a radio). Second, signs of an impending disaster may occur in the middle of the night when most residents are asleep, or during the day when residents are at work or school. Suppose policymakers that are trying to close this gap with limited resources are looking for guidance on whether they do so by extending the reach of the official warning system or by enhancing the community's ability to communicate (and presumably organize) among themselves. This decision cannot be made on anecdotes about heroic organizing effort by ordinary civilians during emergencies; it is important to rigorously investigate whether and why peer-to-peer communication can close this information gap.

A researcher could do this by first comparing compliance, payoffs, and beliefs across Full and Partial (or Full with Observation and Partial with Observation). This will first establish the loss due to the official information gap. The researcher can investigate the impact of communication by measuring outcomes in Partial when 1:1 communication is added or when broadcast ability is added. Analysis of the chat records would provide insight on how the communication capacity is being used and by whom. Researchers can then investigate if these experimental findings can be confirmed in more complex field experiments or site-specific studies before using it to inform policymaking. The findings might be suprising; ex-ante the policymaker might expect that providing any member of the community the ability to reach everyone quickly (Partial with Broadcast) may result in the best outcome. However, experimentation may uncover that these are exactly the kinds of situation where misinformation abounds.

A researcher might go further if she suspects that communication might be hampered by group ties, such as when rivaling ethnic factions directly map to the two districts, or when the line between those who are informed and those who are not are drawn by socio-economic status. Research has found that people communicate different information with their close social contact than with their distant acquaintance. They are also more likely to turn towards and reach out to this same group in an emergency. The researcher can recruit the appropriate population or allow participants to interact before the game to form ties to capture these elements, however, in this environment it would be important to replicate the laboratory findings in a field experiment among the appropriate population.

\section{References}

Abdellaoui, M., \& Kemel, E. (2013). Eliciting prospect theory when consequences are measured in time units:"Time is not money". Management Science, 60(7), 1844-1859. 
Andreoni, J., \& Petrie, R. (2004). Public goods experiments without confidentiality: a glimpse into fund-raising. Journal of public Economics, 88(7), 1605-1623

Au, W. T., Lu, S., Leung, H., Yam, P., \& Fung, J. M. (2012). Risk and Prisoner's Dilemma: A Reinterpretation of Coombs' Re-parameterization. Journal of Behavioral Decision Making, 25(5), 476-490.

Balliet, D., Parks, C., \& Joireman, J. (2009). Social value orientation and cooperation in social dilemmas: A meta-analysis. Group Processes \& Intergroup Relations, 12(4), 533-547.

Bateman, J. M., \& Edwards, B. (2002). Gender and evacuation: A closer look at why women are more likely to evacuate for hurricanes. Natural Hazards Review, 3(3), 107-117.

Benight, C., Gruntfest, E., \& Sparks, K. (2004). Colorado wildfires 2002. Quick Response Research Rep, 167.

Bekkers, R., \& Wiepking, P. (2011). Who gives? A literature review of predictors of charitable giving part one: religion, education, age and socialisation. Voluntary Sector Review, 2(3), 337-365.

Berger, D., Kalyanaraman, S. , \& Linardi , S. (2015). You will hear of skirmishes and rumors of skirmishes: Cell Communication in Proximity to Political Violence. Working paper.

Bode, N. W., Wagoum, A. U. K., \& Codling, E. A. (2014). Human responses to multiple sources of directional information in virtual crowd evacuations. Journal of The Royal Society Interface, 11(91), 20130904.

Bohnet, I., \& Frey, B. S. (1999). Social distance and other-regarding behavior in dictator games: Comment. American Economic Review, 335-339.

Brandts, J., \& Cooper, D. J. (2007). It's what you say, not what you pay: an experimental study of manageremployee relationships in overcoming coordination failure. Journal of the European Economic Association, 5(6), 1223-1268.

Burnside, R. (2006). Leaving the big easy: An examination of the hurricane evacuation behavior of New Orleans residents before Hurricane Katrina. Journal of Public Management and Social Policy, 12(2), 4961 .

Burnside, R., Miller, D. S., \& Rivera, J. D. (2007). The impact of information and risk perception on the hurricane evacuation decision-making of greater New Orleans residents. Sociological Spectrum, 27(6), 727-740.

Candelo, N., Croson, R. \& Eckel, C. (2013). Transmission of information within transnational social networks: A field experiment. Working paper CBEES

Castillo, C., Mendoza, M., \& Poblete, B. (2011, March). Information credibility on twitter. In Proceedings of the 20th international conference on World wide web (pp. 675-684). ACM.

Charness, G., Karni, E., \& Levin, D. (2013). Ambiguity attitudes and social interactions: An experimental investigation. Journal of Risk and Uncertainty, 46(1), 1-25.Chaudhuri, A., Graziano, S., \& Maitra, P. (2006). Social learning and norms in a public goods experiment with inter-generational advice. The Review of Economic Studies, 73(2), 357-380.

Chow, C. C., \& Sarin, R. K. (2001). Comparative ignorance and the Ellsberg paradox. Journal of risk and Uncertainty, 22(2), 129-139.

Comfort, L. K., Ko, K., \& Zagorecki, A. (2004). Coordination in Rapidly Evolving Disaster Response Systems The Role of Information. American Behavioral Scientist, 48(3), 295-313.

Comfort, L. K. (2007). Crisis management in hindsight: Cognition, communication, coordination, and control. Public Administration Review, 67(s1), 189-197.

Deutsch, M. (1958). Trust and suspicion. Journal of conflict resolution, 265-279.

Duflo, E., \& Saez, E. (2002). Participation and investment decisions in a retirement plan: The influence of colleagues' choices. Journal of Public Economics, 85(1), 121-148.

Duflo, E., \& Saez, E. (2003). Implications of information and social interactions for retirement saving decisions. Pension Research Council Working Paper 2003-13, Philadelphia.

Eckel, C. C., \& Grossman, P. J. (2002). Sex differences and statistical stereotyping in attitudes toward financial risk. Evolution and human behavior, 23(4), 281-295. 
Eisenman, D. P., Cordasco, K. M., Asch, S., Golden, J. F., \& Glik, D. (2007). Disaster planning and risk communication with vulnerable communities: lessons from Hurricane Katrina. American journal of public health, 97(Supplement_1), S109-S115.

Fang, Z., Song, W., Zhang, J., \& Wu, H. (2010). Experiment and modeling of exit-selecting behaviors during a building evacuation. Physica A: Statistical Mechanics and its Applications, 389(4), 815-824.

Fehr, E., \& Gintis, H. (2007). Human motivation and social cooperation: Experimental and analytical foundations. Annu. Rev. Sociol., 33, 43-64.

Gino, F., Shang, J., \& Croson, R. (2009). The impact of information from similar or different advisors on judgment. Organizational Behavior and Human Decision Processes, 108(2), 287-302.

Glaeser, E. L., Laibson, D. I., Scheinkman, J. A., \& Soutter, C. L. (2000). Measuring trust. Quarterly Journal of Economics, 811-846.Heath, S. E., Kass, P. H., Beck, A. M., \& Glickman, L. T. (2001). Human and petrelated risk factors for household evacuation failure during a natural disaster. American journal of epidemiology, 153(7), 659-665.

Holbrook, A. L., \& Krosnick, J. A. (2010). Social desirability bias in voter turnout reports Tests using the item count technique. Public Opinion Quarterly, 74(1), 37-67.Jones, D., \& Linardi, S. (2014). Wallflowers: Experimental Evidence of an Aversion to Standing Out. Management Science. 60 (7), 1757-1771

Leider, S., Möbius, M. M., Rosenblat, T., \& Do, Q. A. (2009). Directed altruism and enforced reciprocity in social networks. The Quarterly Journal of Economics, 1815-1851.

Linardi, S., \& McConnell, M. A. (2011). No excuses for good behavior: Volunteering and the social environment. Journal of Public Economics, 95(5), 445-454.

Lindell, M. K., Lu, J. C., \& Prater, C. S. (2005). Household decision making and evacuation in response to Hurricane Lili. Natural Hazards Review, 6(4), 171-179.

Litman, T. (2006). Lessons from Katrina and Rita: What major disasters can teach transportation planners. Journal of Transportation Engineering, 132(1), 11-18

Mobius, M. M., Niehaus, P., \& Rosenblat, T. S. (2005). Social learning and consumer demand. Harvard University, mimeograph. December.

Moussaïd, M., Helbing, D., Garnier, S., Johansson, A., Combe, M., \& Theraulaz, G. (2009). Experimental study of the behavioural mechanisms underlying self-organization in human crowds. Proceedings of the Royal Society B: Biological Sciences, 276(1668), 2755-2762.

Nilsson, D., Johansson, M., \& Frantzich, H. (2009). Evacuation experiment in a road tunnel: A study of human behaviour and technical installations. Fire Safety Journal, 44(4), 458-468.

Ostrom, E. (1990). Governing the commons. Cambridge university press.

Rosenblat, T. S., \& Mobius, M. M. (2004). Getting closer or drifting apart?. The Quarterly Journal of Economics, 971-1009.

Rottenstreich, Y., \& Hsee, C. K. (2001). Money, kisses, and electric shocks: On the affective psychology of risk. Psychological science, 12(3), 185-190.

Schadschneider, A., Klingsch, W., Klüpfel, H., Kretz, T., Rogsch, C., \& Seyfried, A. (2009). Evacuation dynamics: Empirical results, modeling and applications. In Encyclopedia of complexity and systems science (pp. 3142-3176). Springer New York.

Schotter, A., \& Trevino, I. (2014). Belief elicitation in the laboratory. Annu. Rev. Econ., 6(1), 103-128.

Sallee, R. (2005). Evacuation picked apart in Houston: task force zeroes in on traffic flow, fuel supplies, communications and special needs. Houston Chronicle (www. chron. com). Houston.

Smalley, V. J. (2013). Who Says I Should Leave? Factors Determining the Decision to Leave Home During Disasters. Honors Thesis, Paper 356.

Terpstra, T., de Vries, A., Stronkman, R., \& Paradies, G. L. (2012). Towards a realtime Twitter analysis during crises for operational crisis management (pp. 1-9). Simon Fraser University.

Thomson, R., Ito, N., Suda, H., Lin, F., Liu, Y., Hayasaka, R., ... \& Wang, Z. (2012, April). Trusting tweets: The Fukushima disaster and information source credibility on Twitter. In Proceedings of the 9th International ISCRAM Conference (pp. 1-10). 
Umihara, J., \& Nishikitani, M. (2013). Emergent use of Twitter in the 2011 Tohoku Earthquake. Prehospital and disaster medicine, 28(05), 434-440.

Van Assen, M. A. L. M., \& Snijders, C. (2004). Effects of risk preferences in social dilemmas: a gametheoretical analysis and evidence from two experiments. Contemporary psychological research on social dilemmas., 38-65.

Van Lange, P. A., Joireman, J., Parks, C. D., \& Van Dijk, E. (2013). The psychology of social dilemmas: A review. Organizational Behavior and Human Decision Processes, 120(2), 125-141.

Was, J. (2010). Experiments on evacuation dynamics for different classes of situations. In Pedestrian and Evacuation Dynamics 2008 (pp. 225-232). Springer Berlin Heidelberg.

Wit, A. P., \& Kerr, N. L. (2002). " Me versus just us versus us all" categorization and cooperation 